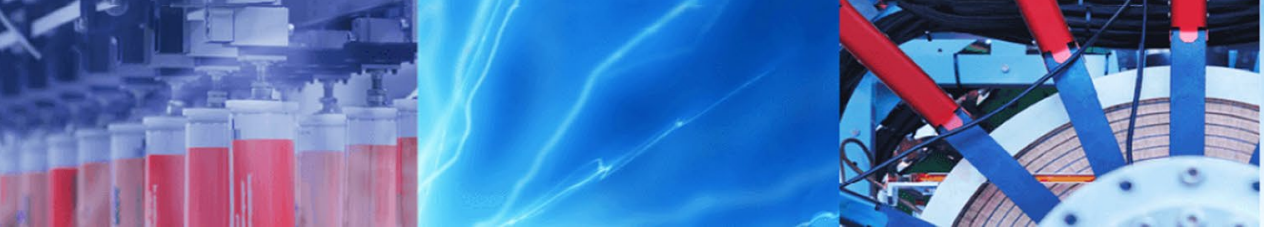

Research Article

\title{
Investigation of rib's effect in cavitation on an axisymmetric separated flow over a longitudinal blunt circular cylinder
}

\author{
Hosein Izadyar ${ }^{1}$ (D) Amir Hossein Aghababaei ${ }^{2} \cdot$ Pezhman Forghani $^{3} \cdot$ Ali Hajighasemi $^{2}$
}

Received: 4 December 2019 / Accepted: 24 February 2020 / Published online: 9 March 2020

(c) Springer Nature Switzerland AG 2020

\begin{abstract}
The current investigation, determines the effects of rib shape and its parameters on an inner flow in which a circular cylinder exist in the middle. The problem is solved in 2 dimensional methods and the distance from the channel's entrance to cylinder is $125 \mathrm{~mm}$. Ansys 14.5 is used for modeling the geometry and meshing of the problem and for modeling the turbulence the $k-\varepsilon$ (realizable) is employed. In this study rib and its four parameters of pitch (p), length (h), rib's height (e) and the distance from the cylinders' head to start of rib (a) in a cavitation flow is investigated. The results show that none of rib's parameters has a direct relation with void fraction. The values for these parameters are different for the maximum or the minimum cavitation; namely if a rib's pitch increases and surpasses a specific value, it will reduce the effect of the previous rib in the flow. In fact, the turbulence eradicates before it become more turbulent by the next rib. On the other hand, if the rib's pitch is too small the flow traps between the two ribs and stagnation happens which is the key element in plummeting the pressure and forming cavity. For other parameters either no correlation with void fraction is observed.
\end{abstract}

Keywords Cavitation · Rib's effect · Void fraction · Turbulent flow

\section{Introduction}

To understand the cavitation phenomenon as a forming and collapsing process of vapor phase in liquid phase in fuel nozzles, theoretical and practical investigation had been conducted. These studies were done to assess the causes and effects of cavitation flows in fuel injections. Cavitation as a process of forming and collapsing vapor bubbles in liquid is an unsteady time dependent phenomenon.

The force cavitation by geometry in channels occurs when pressure fall in channel's entrance is along with flow separation and swirling flow. Existence of flow separation causes the tension distribution which has important role in forming and development of cavitation. While flow separation doesn't occur in low-Reynolds flows, in 1948 Hunter
Rouse and John S. McNown [1] investigated the cavitation in water tunnel with stumbling blocks in different shapes (rectangular, circular, ...). Later on, the cavitation in nozzles was investigated. In 1959, experimental observation on cavitation in nozzles showed the great dependence of cavitation flow to cavitation number and weak correlation with Reynolds number in turbulent flows [2]. These results were for cavitation in axisymmetric nozzles. In 1999, Schmidt showed that in low Reynolds numbers, effect of flow separation in Couette flows are more important [3].

Experimental investigations on cavitation flows in long circular-cylindrical orifices of various throat lengths including the orifice with a trip wire and venturi nozzle as timedependent phenomena were conducted $[4,5]$. Cavitation as a phenomenon with permanent effect has been studied as steady in works of Hunter Rouse and John S. McNown

$\triangle$ Hosein Izadyar, Hoseinizadyar1990@gmail.com; Amir Hossein Aghababaei, Amir.agbb1988@gmail.com; Pezhman Forghani, pezhman.forghani@yahoo.com; Ali Hajighasemi, Alihajighasemi1988@gmail.com | 'Faculty of Mechanical Engineering, University of Shahrekord, Shahrekord, Iran. ${ }^{2}$ Faculty of Mechanical Engineering, Isfahan University of Technology, Khomeyni Shahr, Iran. ${ }^{3}$ Faculty of Mechanical Engineering, Najafabad Branch, Islamic Azad University, Isfahan, Iran. 
[1] or numerical analysis of Bernad et al. [6] on hydrofoils' cavitation. Later it will be shown that steady flow has more correspondence with experimental data. Most of mathematical theories about cavitation is limited to super cavitation because in this regime cavitation is steady and separation of vapor from Couette area doesn't happen. The first studies about super cavitation was conducted by Efros using conformal map [7]. Tulin used perturbation theory to study 2-dimentional super Couettes [8]. Cuthbert and Street [9]. Cuthbert used sources and sinks along the axis of a slender axisymmetric body-cavity system, along with a Riabouchinski cavity closure model. They solved for the unknown cavity shape, but were successful only for a few cases. Chou [10] extended the work of Cuthbert and Street to solve axisymmetric supercavitating flows using slender body theory. He solved the problem by locating sources along the body-cavity axis and control points along the body-cavity surface. Vorus addressed the problem of supercavitating flows using a Laurent series for the cavity shape, resulting in a more realistic cavity closure model, being the lowest-order representation of a re-entrant jet [11]. His results showed differences in the predicted drag compared with those of Chou. Since 1994 two hydrodynamic theory models for axisymmetric Couettes has been presented and developed: Slender axisymmetric body model [12] and finite elements model [13]. The results of both models have been compared with other numerical and experimental results and predicted the cavity shape and length with good accuracy. The slender-body theory model presented in Varghese et al. [12], is essentially an extension of Chou's method. Viscous drag corrections were incorporated and tested using both the Thwaites and Falkner-Skan approximations along the wetted portions of the cavitator, and the effects of subsonic compressible flow were investigated using the compressible Green function. The boundary-element model was employed to examine supercavitating flows past disk-, cone-, and sigma-shaped cavitators.Several researchers such as UhIman Jr JS [14] have modeled partially cavitating flows using nonlinear boundary-element techniques on hydrofoils.

Numerical modeling of cavitation started using potential flow [10] and yet this method is use in many engineering problems. Navier-stocks has been adopted for modeling cavitation in recent years.

Bernad et al. [6] investigated the steady cavitation over a standard 2-D hydrofoil Naca0009 with commercial software FLUENT. In this work, simulations were validated by data over thick hydrofoil and at the end the model used for simulation of cavitation in planar geometry was confirmed. In 2006 Zhang et al. simulated the steady cavitation of fluid nitrogen over a hydrofoil. In their study, in addition to distribution of pressure and void on the flow over the hydrofoil, the effect of temperature on planar cavitation was observed. Salvador et al. conduct numerical modeling of cavitating flow for simple geometries using Fluent V6,1 [15]. In their studies after solving flow field equation for different geometries such as orifice (experiments of [16]), circular nozzle (experiments of [17]) and circular venturi (experiments of [18]), it was found that numerical simulation for steady cavitation is well-correspondent with experimental data while the results for time-dependent cavitation in venturi didn't match the experiments. In their survey, it is noted that the cavitation model in FLUENT 6.1 can be adopted for simple geometries if the flow is considered steady. Senocak et al. presented a cavitation model and evaluated it through steady cavitation over different solid objects such as spherical, finger shaped, hydrofoil NACA66M and convergent divergent nozzle [19]. Afterwards, they evaluated their model as time-dependent over cylinder and venturi. However in this case Couette instabilities didn't discussed and they just talked about pressure.

As for rib, web et al. [20] in 1971, Han et al. [21] in 1978, Gee [22] Sethumadhavan et al. [23] used rib to increase the turbulence in different duct shapes such as rectangular, circular and surveyed the effects of pitch, rib's height in Enhancement of Heat Transfer for a wide range of Reynolds numbers. Hann et al. [24] performed experimental study of fully developed turbulent air flow in square ducts with two opposite rib-roughened walls to determine the effects of the rib pitch-to-height and rib height-to-equivalent diameter ratios on friction factor and heat transfer coefficients with Reynolds number varied between 7000 and 90,000.

In this study the effect of rib in cavitation of water in water channel containing a circular cylinder in the middle was studied. Most of studies about cavitation has been performed only in nozzles in experiments. Also time-dependent numerical simulation of cavitation has been limited to outer flow over hydrofoils and spherical shapes. Also most of the studies has been performed about steady planar cavitation. However, considering the characteristics of cavitation, having knowledge of instabilities in such flows, to ideally design and controlling the bad effects of cavitation, is indispensable. For this purpose, in this study the effect different parameters of rib on an inner flow in which a circular cylinder exist is surveyed and effect of four rib's parameters (rib's pitch, rib's height, rib's length and distance from cylinder to rib's start) on the flow's turbulence, decrease or increase of cavitation and on cavitation was analyzed.

\section{Numerical method}

\subsection{Geometry}

The physical model that was adopted for this study is shown in Fig. 1. Floating cylinder's diameter is $250 \mathrm{~mm}(\mathrm{~d}=250 \mathrm{~mm}$ ). 
Dimensions of channel is $5 \mathrm{~d} \times 17 \mathrm{~d}$. The problem is solved 2-dimentional and the distance from the beginning of the channel to the cylinder is $125 \mathrm{~mm}$. Four other parameters, namely, pitch $(p)$, length $(h)$ rib's height(e) and distance from cylinder to the start of rib(a) also will be investigated.

\subsection{Governing equations}

General Navier-Stokes and continuity equations for solving a limited domain in a cavity, like the case studies in [25-27], is developed for the current study. When cavitation happens in the field, modeling the cavitation is essential. In this case a new equation for the volume fraction $a$ is solved and thus the field is divided into 3 parts:

$\alpha(x, t)= \begin{cases}1 & \text { primary phase } \\ 0 & \text { seconsary phase } \\ 0<\alpha<1 & \text { interaction between phases }\end{cases}$

Most of the computational domain constrains only liquid, $a=0$, but within the region with $p>p_{v}$ the vapor phase is formed with $0<a<1$.

So density and the viscosity of mixture can be written as below:

$\rho=\alpha \rho_{1}+(1-\alpha) \rho_{2}$

$\mu=\alpha \mu_{1}+(1-\alpha) \mu_{2}$

Continuity equation:

$\frac{\partial \rho}{\partial t}+\nabla \cdot(\rho c)=0$

Using (3) we have:

$\left(\rho_{l}-\rho_{v}\right)\left(\frac{\partial \alpha}{\partial t}+\nabla \cdot(\alpha c)\right)+\rho_{v} \nabla \cdot c=0$

By introducing $S_{a}$ and $S_{m}$ as source terms of equations of volume fraction and velocity divergence:

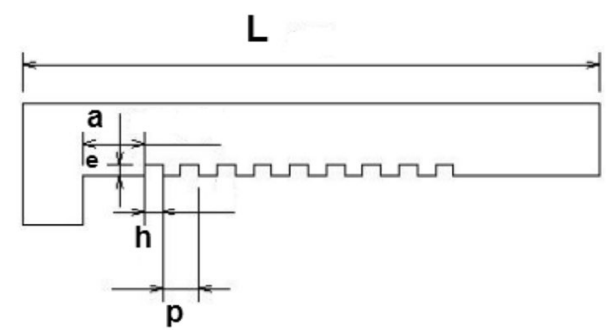

Fig. 1 Schematic model $\frac{\partial \alpha}{\partial t}+\nabla \cdot(\alpha c)=S_{a}$

And putting (4) into Eq. (3):

$S_{m}=-\frac{\left(\rho_{l}-\rho_{v}\right)}{\rho_{v}} S_{a}$

The operating conditions are given in Table 1. The vapor pressure is water vapor pressure in temperature of $295^{\circ}$ kelvin. Index $v$ is for vapor phase and index I is for liquid phase.

Boundary condition is shown in Fig. 2. The Inlet velocity is $10 \mathrm{~m} / \mathrm{s}$ and the pressure of $18,540 \mathrm{~Pa}$ is imposed in outlet to ensure that the planar cavitation happens.

\subsection{Turbulence model}

In these calculations turbulence effects were considered using turbulence models, as the $\mathrm{k}-\varepsilon$ (realizable) models, with the modification of the turbulent viscosity for multiphase flow [28].

An immediate benefit of the realizable $k-\varepsilon$ model is that it more accurately predicts the spreading rate of both planar and round jets. It is also likely to provide superior performance for flows involving rotation, boundary layers under strong adverse pressure gradients, separation, and recirculation. Realizable $\mathrm{k}-\varepsilon$ demonstrates a superior ability to capture the mean flow of the complex structures.

To model the flow close to the wall, standard wall-function approach was used, then the enhanced wall functions approach has been used to model the near-wall region in which standard wall function becomes less reliable (i.e., laminar sublayer, buffer region, and fully-turbulent outer region).

Table 1 Operating conditions

\begin{tabular}{lll}
\hline$\rho_{l}=1000 \mathrm{~kg} / \mathrm{m}^{3}$ & $\vartheta_{l}=0.001 \mathrm{~kg} / \mathrm{ms}$ & $P_{V}=2500 \mathrm{pa}$ \\
$\rho_{v}=0.02 \mathrm{~kg} / \mathrm{m}^{3}$ & $\vartheta_{v}=10^{-5} \mathrm{~kg} / \mathrm{ms}$ & $T_{\text {ref }}=295 \mathrm{~K}$ \\
\hline
\end{tabular}

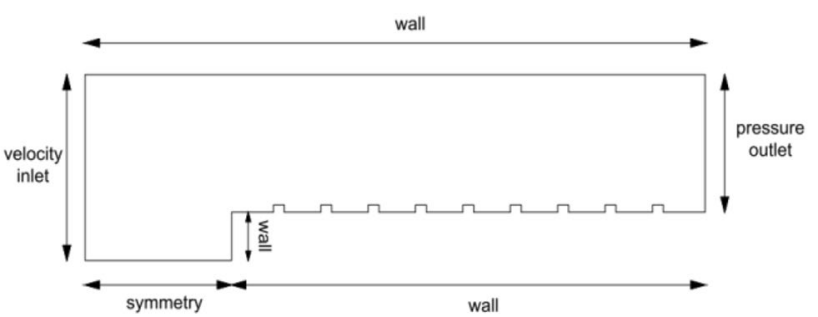

Fig. 2 Boundary condition 
$\rho \frac{\partial k}{\partial t}+\rho u_{j} k_{i j}=\left(\propto+\frac{\alpha_{t}}{\sigma_{k}} k_{i j}\right)+G+B-\rho \varepsilon$

$\frac{\partial \varepsilon}{\partial t}+\rho u_{j} \varepsilon_{, j}=\left(\alpha+\frac{\alpha_{t}}{\sigma_{\varepsilon}} \varepsilon_{, j}\right)+C_{1} \frac{\varepsilon}{k} G-C_{1}\left(1-C_{3}\right) \frac{\varepsilon}{k}-C_{2} \rho \frac{\varepsilon^{2}}{k}-\frac{C_{\alpha} \eta^{3}\left(1-\frac{\eta}{\eta_{0}}\right)}{1+\beta \eta^{3}} \frac{\varepsilon^{2}}{k}$

The empirical constants for the turbulence model are assigned the following base on [29]:

$\mathrm{C} \mu=0.09, \mathrm{C} 1=1.47, \mathrm{C} 2=1.92 \sigma \mathrm{k}=1.0, \sigma \varepsilon=1.3$

Non-equilibrium wall functions is imposed on the wall:

$$
\begin{aligned}
& \frac{\bar{U} C_{\alpha}^{1 / 4} k_{p}^{1 / 2}}{\tau_{w / \rho}}=\frac{1}{\kappa} \ln \left(E \frac{C_{\alpha}^{1 / 4} k_{p}^{1 / 2} y}{\propto}\right) \\
& \bar{U}=U-\frac{1}{2} \frac{d p}{d x}\left[\frac{y_{v}}{\rho \kappa \sqrt{ } k} \ln \left(\frac{y}{y_{v}}\right)+\frac{y-y_{v}}{\rho \kappa \sqrt{ }}+\frac{y_{v}^{2}}{\alpha}\right] \\
& y_{v} \equiv \frac{\propto y_{v}^{*}}{\rho C_{\alpha}^{1 / 4} k_{p}^{1 / 2}}
\end{aligned}
$$

And $\mathrm{y}_{\mathrm{v}}^{*}=11.225$

\section{Solution strategy}

For meshing and modeling the Ansys 14.5 is used. As the simulation is handled steady, the Schnerr-Sauer model [30] is adopted since this model is suitable for planar cavitation an also in their formulation of mass transfer rate is able to simulate the cyclic formation of cavitation cloud, the formation of re-entrant jet, and so on. To validate the simulations, a comparison with experimental results of Singhal et al. [31] is made. Figure 3 shows the geometry and boundary condition of simulation for cavitating around a 2-D plane. The apex angle is 45 , diameter of cylinder is $0.025 \mathrm{~m}$ and its length is $0.3 \mathrm{~m}$ and distance between to walls is $5 d$. Because of the symmetry of the geometry around the axis of the cylinder, the simulations are done in 2-D axisymmetric. In this study the planar cavitation (cavi- tation number is 0.3 ) is studied. The inlet velocity is $10 \mathrm{~m} / \mathrm{s}$ and constant. By setting outlet pressure for 18,540 $\mathrm{Pa}$ and the inlet velocity of $10 \mathrm{~m} / \mathrm{s}$, the cavitation number would be 0.3 which causes the planar cavitation [2].

In Fig. 4 the pressure coefficient over the apex of the cone is plotted and compared with experimental data of Singhal et al. It was found that the results from numerical simulation has a good agreement with experimental data.

A uniform 2-D mesh was performed and near the ribs' walls it was refined. Figure 5 shows the grid system used for simulation.

In the code, the finite volume method was employed to discretize all differential equations and the algorithm of pressure implicit with splitting of operators (PISO) was adopted for nonlinear iterations of pressure and velocity solutions. The PISO algorithm is efficient and more accurate to solve the Navier-Stokes equations in unsteady problems because the momentum corrector step is performed more than once, compared to the traditional SIMPLE algorithm For spatial discretization, the quadratic upwind interpolation for convective kinematics (QUICK) scheme [32] is used, which is based on a weighted average of second-order upwind and central interpolations of the dependent variables. The QUICK scheme works best with structured meshes and also for non-hexahedral or nonquadrilateral cells in unstructured meshes.

In order to verify the independence of the solution on the mesh size, calculations were also made with 3 different grids of 22,500 cells, 90,000 cells and 360,000 cells. The velocity of flow in the distance of $0.175 \mathrm{~m}$ were compared.

Figure 6 shows the results of the study.

These gave negligible differences from the finer mesh results; hence, proving grid independence.
Fig. 3 Geometry and boundary condition

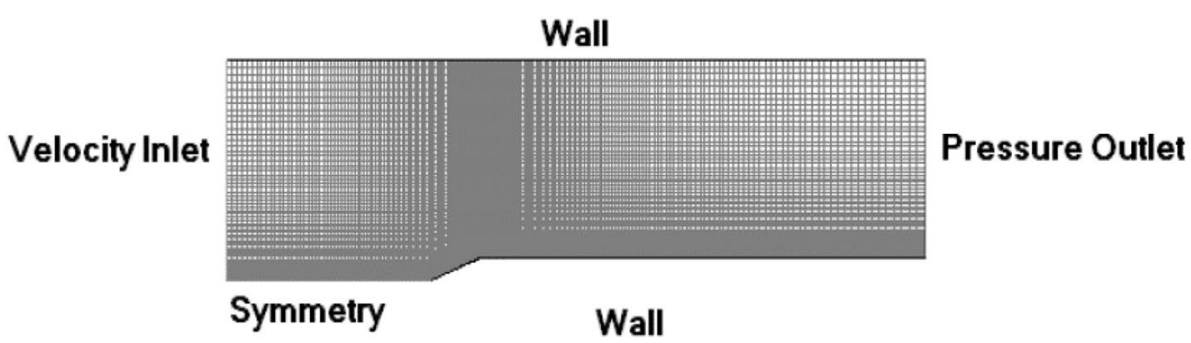


Fig. 4 Pressure coefficient over the apex of the cone

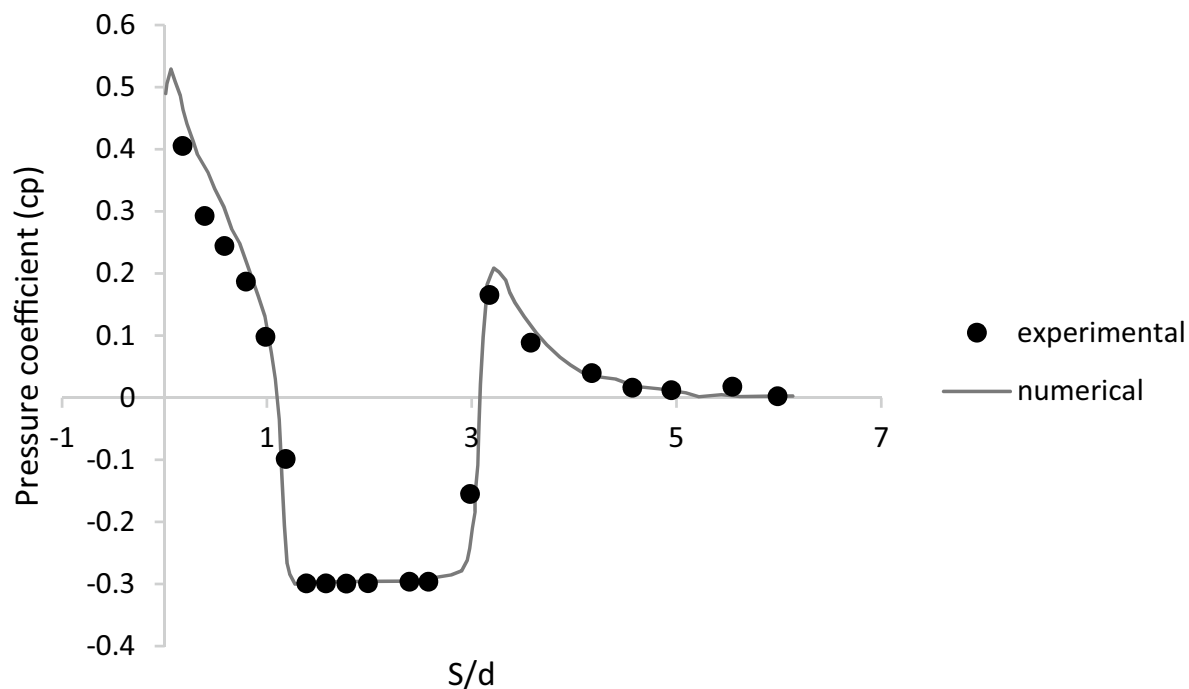

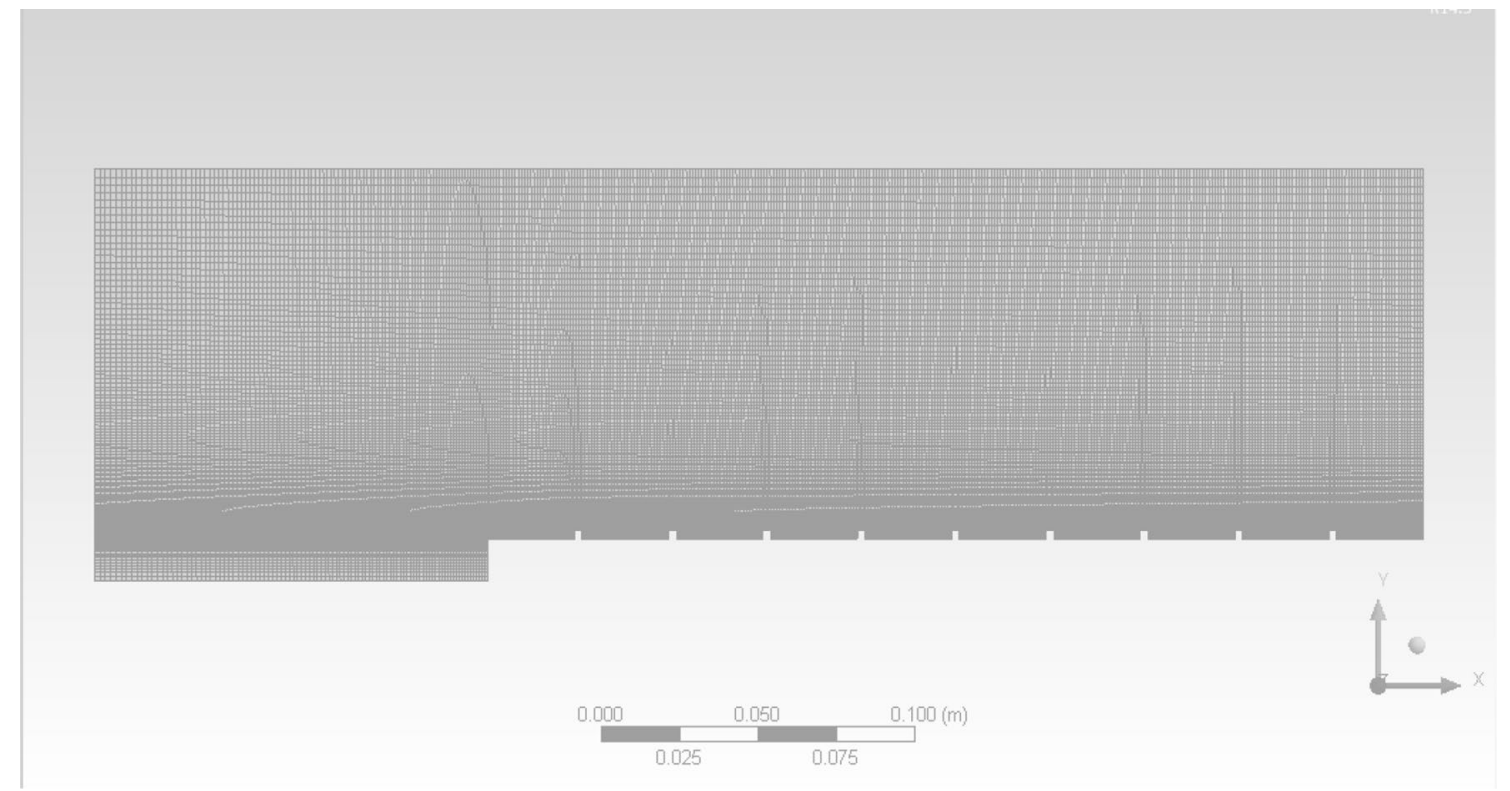

Fig. 5 Grid system

Figure 7 shows the $\mathrm{y}^{+}$on the wall for the mixture. It is desirable that $\mathrm{y}^{+}$alters between 30 and 500 . As it can be seen, the $\mathrm{y}^{+}$in this study differs from 32 to 82 which shows that chosen wall functions are suitable.

\section{Results and discussion}

In this segment a comparison is made between two cases: one with ribs and the other without ribs.

In Fig. 8 volume fraction contour for two cases of with and without rib is shown. As can be seen, cavitation happens more in absence of ribs. However, volume fraction is not ideally a suitable factor to study cavitation. For better comprehending of cavitation in flow, it's needed to introduce a parameter which shows the vapor produced throughout the channel. Thus, the VF parameter is introduced as below:

$\overline{\mathrm{VF}}=\frac{1}{\mathrm{~A}} \int \mathrm{VFdA}$.

Which shows the exact amount of mass changed to vapor per area in comparison to total mass. For the case in which 


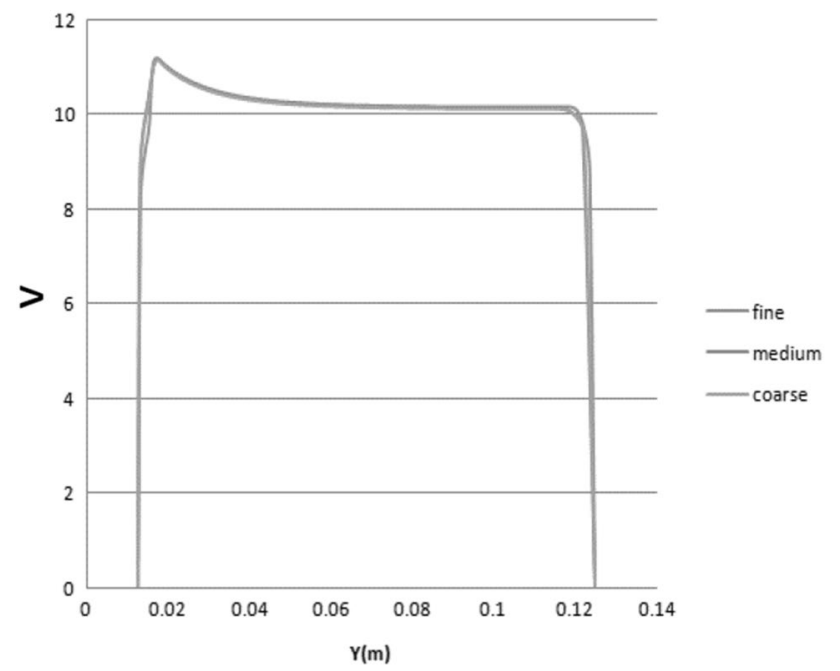

Fig. 6 Velocity of flow in the distance of $0.175 \mathrm{~m}$ for three different meshes

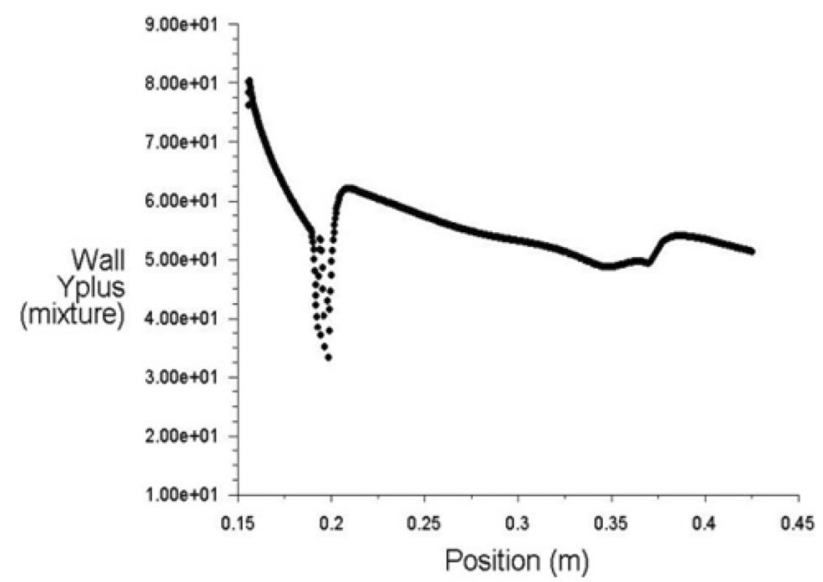

Fig. 7 The $y^{+}$on the wall for the mixture there is no rib, this parameter is equal to $0.0,056,485$ which is called $\overline{\mathrm{VF}}_{\mathrm{f}}$.the volume fraction of the with-rib case for $\mathrm{p} / \mathrm{d}=1.2, \mathrm{a} / \mathrm{d}=1, \mathrm{e} / \mathrm{d}=0.05$ and $\mathrm{h} / \mathrm{d}=0.12$ is shown in Table 2 . As it can be seen, rib causes to reduce the volume fraction of vapor.

Figure 9 shows the turbulence kinetic energy in two cases.

\subsection{Effect of rib's parameters on cavitation and flow}

In this section the effects of rib's parameters (rib's pitch(p), rib's height(e), rib's length(h) and distance from cylinder to rib's start(a)) on cavitation are studied.

\subsubsection{Parameter "a"}

This parameter shows the distance from the start of rib to cylinder. Two series of simulation were done to investigate this parameter more precisely. In Table 3 other parameters of rib for two groups are written. In Fig. 10 changes of $\overline{\mathrm{VF}}_{f}$ in case of changes in "a" is plotted.

It can be clearly observed that changes in parameter "a" doesn't have any direct correlation with cavitation. In fact, very low numbers of "a" narrow the flow route and therefore causes more pressure drop. On the other hand, increasing of "a" leads to increase in flow's turbulence and pressure drop which is happened because of cylinder, effects the flow without any influence from rib. Hence parameter "a" is not associated directly with cavitation.

\subsubsection{Parameter "p"}

This parameter represents the rib's pitch. Table 4 shows the other parameters in two groups in which changes of " $p$ " has been studied. (a)

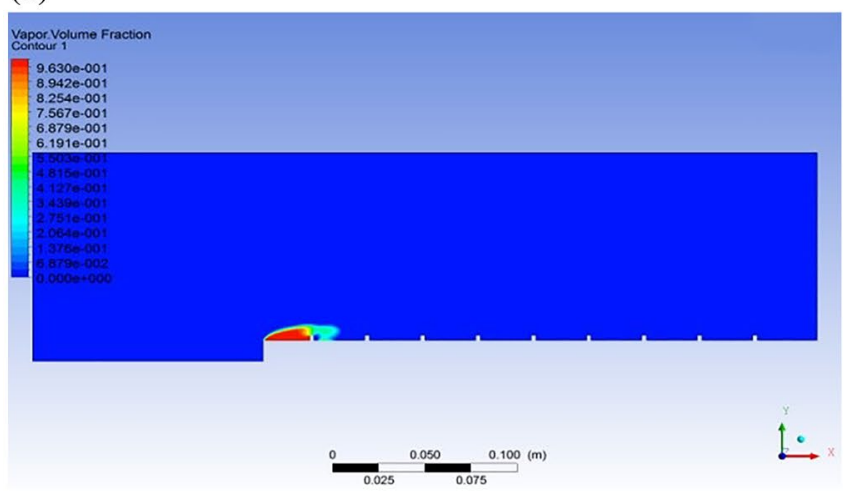

(b)

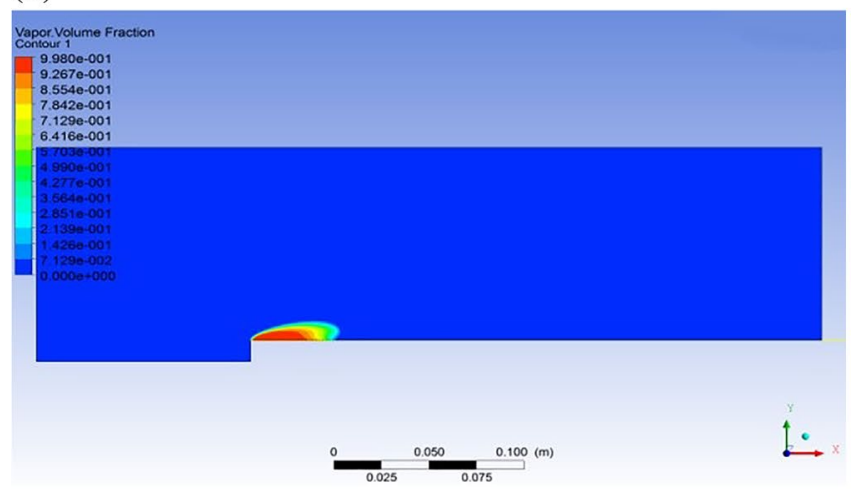

Fig. 8 Volume fraction contour for $\mathbf{a}$ case of with rib and $\mathbf{b}$ case of without rib

SN Applied Sciences 
Table 2 Comparison of volume fraction in two cases

\begin{tabular}{ll}
\hline $\mathrm{VF} / \mathrm{VF}_{\text {ref }}$ & $\mathrm{VF}$ \\
\hline 0.64 & 0.00364
\end{tabular}

Table 4 Parameters of rib for two group

\begin{tabular}{llll}
\hline & $\bar{a}$ & $\bar{e}$ & $\bar{h}$ \\
\hline First series & 1 & 0.12 & \\
Second series & 1 & 0.16 & 0.1
\end{tabular}

(a)

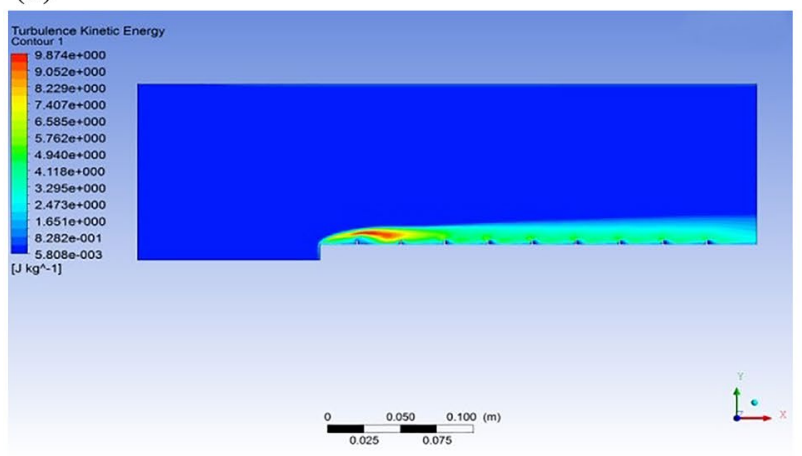

(b)

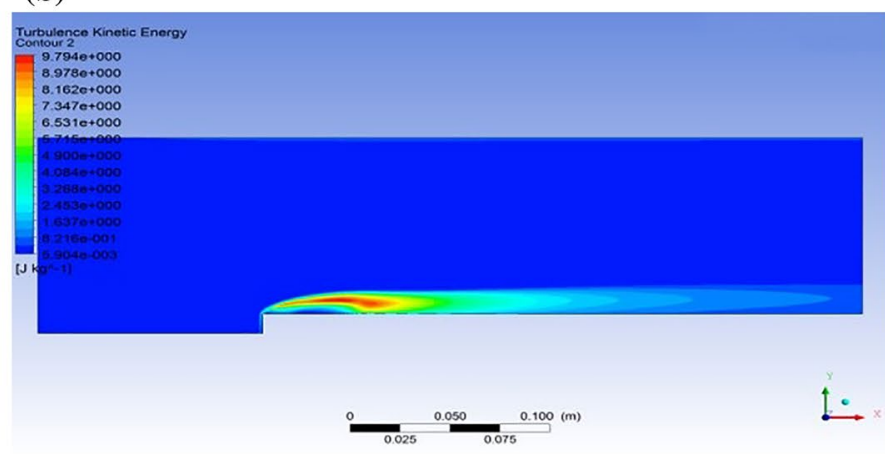

Fig. 9 Turbulence kinetic energy for $\mathbf{a}$ case of with rib and $\mathbf{b}$ case of without rib

Table 3 Parameters of rib for two groups

\begin{tabular}{llll}
\hline & $\bar{p}$ & $\bar{p}$ & $\bar{h}$ \\
\hline First series & 1.2 & 0.1 & \\
Second series & 1 & 0.12 & 0.1 \\
\hline
\end{tabular}

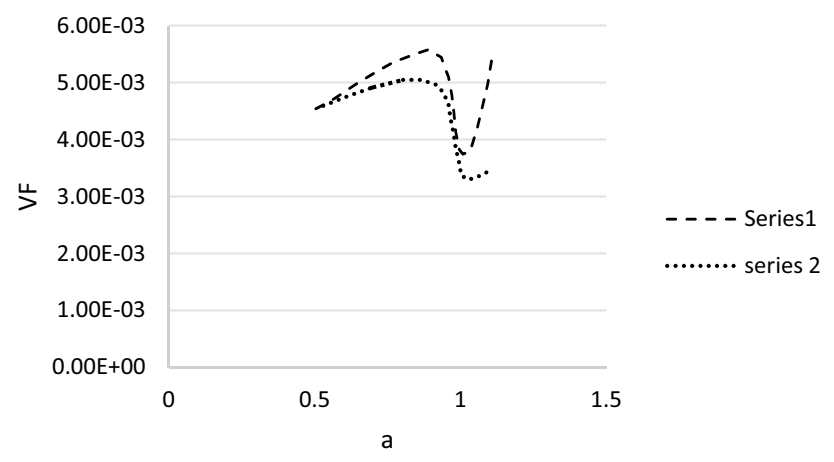

Fig. 10 Changes of $\overline{\mathrm{VF}}_{\text {ref } f}$

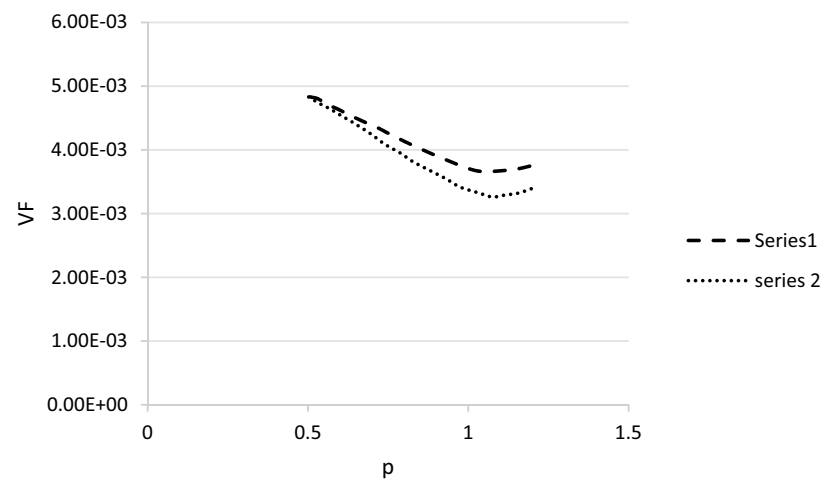

Fig. 11 Changes of $\overline{\mathrm{VF}}_{\text {ref } f}$

Table 4 shows the changes of $\overline{\mathrm{VF}}_{\mathrm{f}}$ in case of changes in "p".

The diagram reveals that there is no direct connection between " $p$ " and volume fraction of vapor. In point of fact, increase in rib's pitch makes the rib's turbulence ineffective. It means that the turbulent made by the first rib would diminish if the rib's pitch is high (Fig. 11).

\subsubsection{Parameter "e"}

This parameter shows the rib's height. Table 5 shows the other parameters in two groups in which changes of " $\mathrm{e}$ " has been studied. Also in Fig. 12 the relation between $\overline{\mathrm{VF}}$ $f$ and " $p$ " is shown.

As is presented in diagram, rib's height and volume fraction of vapor are not connected directly to each other. Very low amount of parameter " $\mathrm{e}$ " is similar to the no-rib case and increase in it can cause severe pressure drop and cavitation. So to reduce cavitation an optimum height for rib should be considered.

\subsubsection{Parameter " $h$ "}

This parameter represents the rib's length. Table 6 shows the other parameters in two groups in which changes of " $\mathrm{h}$ " has been studied. Also in Fig. 13 the relation between $\overline{\mathrm{VF}}_{\mathrm{f}}$ and "h" is shown.

Table 5 Parameters of rib for two group

\begin{tabular}{llll}
\hline & $\bar{a}$ & $\bar{p}$ & $\bar{h}$ \\
\hline First series & 1.1 & 1.2 & \\
Second series & 1 & 1 & 0.1 \\
\hline
\end{tabular}




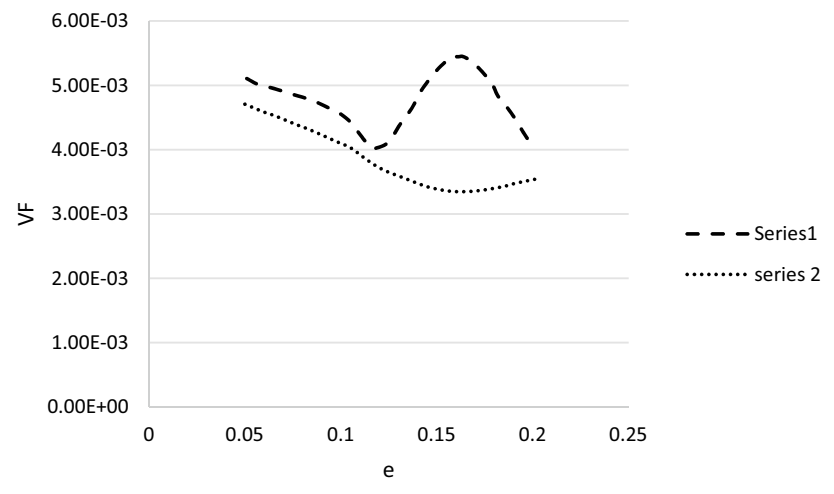

Fig. 12 Changes of $\overline{\mathrm{VF}}_{\text {ref } f}$

Table 6 Parameters of rib for two group
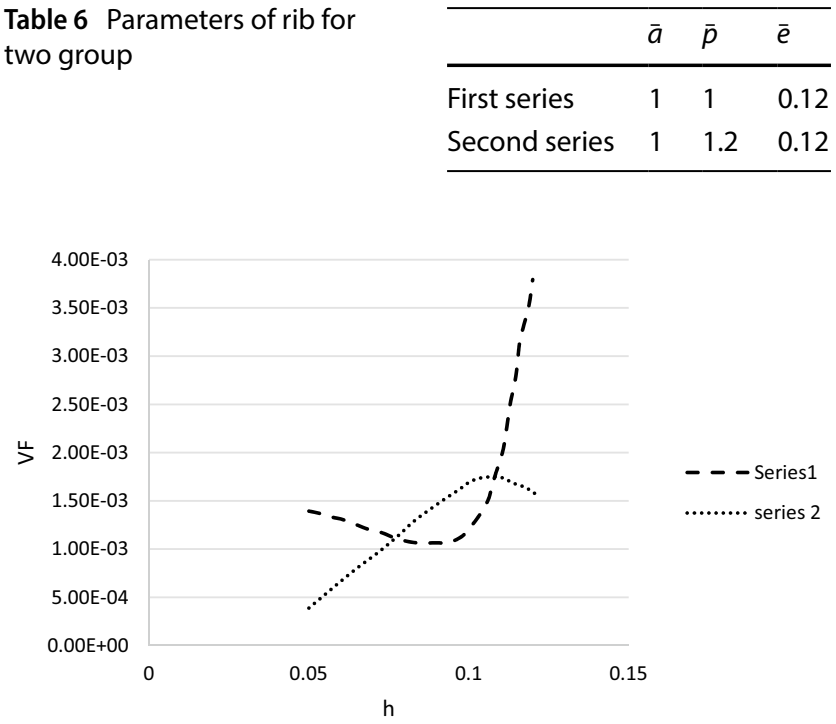

Fig. 13 Changes of $\overline{\mathrm{VF}}_{\text {ref } f}$

It could be plainly viewed that rib's length is not directly related to $\overline{\mathrm{VF}}_{\text {ref }}$. It's impact is similar to effect of rib's pitch and increase of it can eradicate the turbulence of previous ribs and decrease in it can cause flow stagnation and pressure drop. Thus an optimum quantity should be taken into account to reduce cavitation.

\section{Conclusions}

In this study effects of rib and its parameters on an inner flow through a duct in which a circular cylinder in placed in the middle was studied. Computational fluid dynamics software (ANSYS 14.5) was used for numerical computation. The rib's parameters' effects on flow and cavitation was surveyed. Results revealed that none of rib's parameters (rib's pitch(p), rib's height(e), rib's length(h) and distance from cylinder to rib's start(a)) has a direct relation with volume fraction of vapor. Magnitude of each parameter for maximum or minimum cavitation is different. As for the rib's pitch, if the size of pitch is too ample, it leads to eradication of previous rib in the flow. In contrast by decreasing it to very small sizes, flow would trap between two ribs and cause stagnation which gives rise to cavitation in flow. Other parameters also are the same and none has direct correlation with cavitation.

\section{Compliance with ethical standards}

Conflict of interest The authors declare that they have no conflict of interest.

\section{References}

1. Rouse H, McNown JS (1948) Cavitation and pressure distribution: head forms at zero angle of yaw

2. Bergwerk W (1959) Flow pattern in diesel nozzle spray holes. Proc Inst Mech Eng 173(1):655-660

3. Schmidt DP, Rutland CJ, Corradini ML (1999) A fully compressible, two-dimensional model of small, high-speed, cavitating nozzles. Atom Sprays 9(3):255-276

4. Roosen P, Unruh O, Behman M (1997) Investigation of cavitation phenomena inside fuel injector nozzles. In: 30th International Symposium on Automotive Technology \& Automation, ISATA, Florence, Italy, 16th-19th June 1997

5. Sato K, Saito Y (2002) Unstable cavitation behavior in a circularcylindrical orifice flow. JSME Int J Ser B 45(3):638-645

6. Bernad S, Susan-Resiga R, Muntean S, Anton I (2006) Numerical analysis of the cavitating flows. In: Proceedings of the Romanian Academy, Serie A 7

7. Efros D (1946) Hydrodynamic theory of two-dimensional flow with cavitation. In: Dokl. Akad. Nauk SSSR, pp 267-270

8. Tulin MP (1963) Supercavitating flows-small perturbation theory. Hydronautics Inc Laurel MD

9. Cuthbert J, Street R (1964) An approximate theory for supercavitating flow about slender bodies of revolution. Lockheed Missiles and Space Co, Sunnyvale, LMSC Report No TM81-73/39

10. Chou YM (1974) Axisymmetric cavity flows past slender bodies of revolution. J Hydronaut 8(1):13-18

11. Vorus W (1991) A theoretical study of the use of supercavitation/ventilation for underwater body drag reduction. Vorus and Associates Inc, Gregory

12. Varghese A, Uhlman J, Kirschner I (1997) Axisymmetric slenderbody analysis of supercavitating high-speed bodies in subsonic flow. In: Proceedings of the 3rd international symposium on performance enhancement for marine applications, Newport

13. Kirschner IN, UhIman J, Varghese AN, Kuria IM (1995) Supercavitating projectiles in axisymmetric subsonic liquid flows. ASME Publications FED 210:75-94

14. Uhlman JS Jr (1987) Partially cavitating hydrofoils. J Ship Res 31(2):107-124

15. Palau-Salvador G, Altozano PG, Arviza-Valverde J (2007) Numerical modeling of cavitating flows for simple geometries using FLUENT. Span J Agric Res 5(4):460-469

16. Nurick W (1976) Orifice cavitation and its effect on spray mixing

17. Delannoy Y, Kueny J (1990) Cavity flow predictions based on the Euler equations. In: ASME cavitation and multi-phase flow forum, pp 153-158

18. Franc J, Michel J (2004) Fundamentals of cavitation, 115. Kluwer Academic Publisher, Netherlands Section 6(1) 
19. Wang G, Senocak I, Shyy W, Ikohagi T, Cao S (2001) Dynamics of attached turbulent cavitating flows. Prog Aerosp Sci 37(6):551-581

20. Webb R, Eckert E, Goldstein R (1971) Heat transfer and friction in tubes with repeated-rib roughness. Int J Heat Mass Transf 14(4):601-617

21. Han J-C, Glicksman L, Rohsenow W (1978) An investigation of heat transfer and friction for rib-roughened surfaces. Int J Heat Mass Transf 21(8):1143-1156

22. Gee DL, Webb R (1980) Forced convection heat transfer in helically rib-roughened tubes. Int J Heat Mass Transf 23(8):1127-1136

23. Sethumadhavan R, Rao MR (1983) Turbulent flow heat transfer and fluid friction in helical-wire-coil-inserted tubes. Int J Heat Mass Transf 26(12):1833-1845

24. Han J (1984) Heat transfer and friction in channels with two opposite rib-roughened walls. J Heat Transf 106(4):774-781

25. Arumuga Perumal D, Dass Anoop K (2011) Multiplicity of steady solutions in two-dimensional lid-driven cavity flows by lattice Boltzmann method. Comput Math Appl 61(12):3711-3721. https://doi.org/10.1016/j.camwa.2010.03.053

26. Mortazavian E, Wang Z, Teng H (2018) Thermal-mechanical study of $3 \mathrm{D}$ printing technology for rail repair. Volume 2: advanced manufacturing, V002T02A052. ASME. https://doi.org/10.1115/ IMECE2018-86315

27. Kalita Jiten C, Gogoi Bidyut B (2014) Global two-dimensional stability of the staggered cavity flow with an HOC approach. Comput Math Appl 67(3):569-590. https://doi.org/10.1016/j. camwa.2013.12.001

28. Shih T-H, Liou WW, Shabbir A, Yang Z, Zhu J (1995) A new k- $-\varepsilon$ eddy viscosity model for high reynolds number turbulent flows. Comput Fluids 24(3):227-238

29. Ghorai S, Nigam K (2006) CFD modeling of flow profiles and interfacial phenomena in two-phase flow in pipes. Chem Eng Process 45(1):55-65

30. Schnerr GH, Sauer J (2001) Physical and numerical modeling of unsteady cavitation dynamics. In: Fourth international conference on multiphase flow, ICMF New Orleans

31. Singhal AK, Athavale MM, Li H, Jiang Y (2002) Mathematical basis and validation of the full cavitation model. J Fluids Eng 124(3):617-624

32. Ferziger JH, Peric M (2012) Computational methods for fluid dynamics. Springer, Berlin

Publisher's Note Springer Nature remains neutral with regard to jurisdictional claims in published maps and institutional affiliations. 